\title{
First isolation and characterization of Brucella microti from wild boar
}

\author{
Zsuzsanna Rónai ${ }^{*}$, Zsuzsa Kreizinger², Ádám Dán ${ }^{1}$, Kevin Drees ${ }^{3}$, Jeffrey T. Foster ${ }^{3}$, Krisztián Bányai ${ }^{2}$, Szilvia Marton², \\ Levente Szeredi ${ }^{1}$, Szilárd Jánosi ${ }^{1}$ and Miklós Gyuranecz ${ }^{2}$
}

\begin{abstract}
Background: Brucella microti was first isolated from common vole (Microtus arvalis) in the Czech Republic in Central Europe in 2007. As B. microti is the only Brucella species known to live in soil, its distribution, ecology, zoonotic potential, and genomic organization is of particular interest. The present paper is the first to report the isolation of B. microti from a wild boar (Sus scrofa), which is also the first isolation of this bacterial species in Hungary.

Results: The B. microti isolate was cultured, after enrichment in Brucella-selective broth, from the submandibular lymph node of a female wild boar that was taken by hunters in Hungary near the Austrian border in September 2014. Histological and immunohistological examinations of the lymph node sections with B. abortus-, B. suis- and $B$. canis-specific sera gave negative results. The isolate did not require $\mathrm{CO}_{2}$ for growth, was oxidase, catalase, and urease positive, $\mathrm{H}_{2} \mathrm{~S}$ negative, grew well in the presence of $20 \mathrm{\mu g} / \mathrm{ml}$ basic fuchsin and thionin, and had brownish pigmentation after three days of incubation. It gave strong positive agglutination with anti-A and anti-M but had a negative reaction with anti-R monospecific sera. The API 20 NE test identified it as Ochrobactrum anthropi with $99.9 \%$ identity, and it showed B. microti-specific banding pattern in the Bruce- and Suis-ladder multiplex PCR systems. Whole genome re-sequencing identified 30 SNPs in orthologous loci when compared to the $B$. microti reference genome available in GenBank, and the MLVA analysis yielded a unique profile.

Conclusions: Given that the female wild boar did not develop any clinical disease, we hypothesize that this host species only harboured the bacterium, serving as a possible reservoir capable of maintaining and spreading this pathogen. The infectious source could have been either a rodent, a carcass that had been eaten or infection occurred via the boar rooting in soil. The low number of discovered SNPs suggests an unexpectedly high level of genetic homogeneity in this Brucella species.
\end{abstract}

Keywords: Biochemistry, Brucella microti, Immunohistochemistry, MLVA, Morphology, Wild boar, Whole genome sequencing, Hungary

\section{Background}

The genus Brucella gained numerous new members in recent years. Brucella ceti and B. pinnipedialis have been isolated since the mid-1990's from marine mammals but were only named and designated in 2007 [1]. B. inopinata was described in 2010 [2], 'atypical' Brucella strains from frogs in 2012 and 2015 [3, 4], and the most recent member of the genus is B. papionis, which was isolated from baboons [5].

\footnotetext{
*Correspondence: ronai.zsuzsanna@gmail.com

'Veterinary Diagnostic Directorate, National Food Chain Safety Office, P.O. Box 21581 Budapest, Hungary

Full list of author information is available at the end of the article
}

Hubalek et al. [6] reported brucellosis in common voles (Microtus arvalis) in the Czech Republic, and the pathogen was described as B. microti [7]. Since then it has been detected in soil samples [8] and lymph nodes of red foxes [9] in the Czech Republic and Austria. The whole genome sequence of the type strain CCM $4915^{\mathrm{T}}$ was published in 2009 [10], its pathogenic potential was investigated in murine models [11], and the intraspecies biodiversity of the species was investigated by $\mathrm{Al}$ Dahouk and colleagues [12]. As B. microti is the only Brucella species known to persist in soil, it is of particular interest as an environmental reservoir and data on

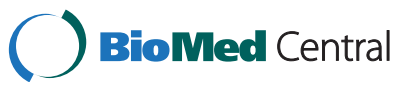

(c) 2015 Rónai et al. This is an Open Access article distributed under the terms of the Creative Commons Attribution License (http://creativecommons.org/licenses/by/4.0), which permits unrestricted use, distribution, and reproduction in any medium, provided the original work is properly credited. The Creative Commons Public Domain Dedication waiver (http:// creativecommons.org/publicdomain/zero/1.0/) applies to the data made available in this article, unless otherwise stated. 
the distribution, ecology, zoonotic potential, genomic organization of this bacterium and relatedness to other strains are urgently needed [12].

A B. microti strain was isolated from the submandibular lymph node of a female wild boar (Sus scrofa) in Hungary near Rajka town $\left(47.9^{\circ} \mathrm{N}, 17.2{ }^{\circ} \mathrm{E}\right)$ in close vicinity to the Austrian border in September, 2014. This is the first isolation of $B$. microti from wild boar. The aim of the study was to describe the isolation conditions and to determine the morphological, biochemical, and genetic characteristics of the isolate and compare it with previous $B$. microti isolates originating from different host species.

\section{Methods}

The submandibular lymph node of a hunted female wild boar was collected as part of the national wildlife health monitoring programme and submitted for routine diagnostic examination, therefore ethical approval was not required for the study. After gross pathological examination, half of the lymph node was fixed in $8 \%$ formalin and embedded in paraffin for hematoxylin-eosin, and immunohistochemical examinations as described previously [13]. In brief, 4- $\mu \mathrm{m}$ thick deparaffinized serial sections were incubated overnight at $4{ }^{\circ} \mathrm{C}$ with $B$. abortus-specific (S type Brucella species'), B. canis-specific ( $\mathrm{R}$ type Brucella species') hyperimmune rabbit serum or B. suis-specific (S type Brucella species') hyperimmune mouse serum diluted to 1:100.000, 1:20.000, and 1:40.000 respectively, and antibody binding was detected by a horseradish peroxidase-labeled polymer (EnVision + Kit, Dako Denmark A/S, Glostrup, Denmark).

The other half of the lymph node was sliced up and mixed with $10 \mathrm{ml}$ phosphate buffered saline, then homogenized with a laboratory blender ( $5 \mathrm{~min}$ at blending speed of 10 strokes/sec; BagMixer $400 \mathrm{VW}$, InterScience, Saint Nom, France). Selective Brucella agar plates (Oxoid Ltd., Cambridge, United Kingdom) containing $5 \%$ heat inactivated horse serum (Invitrogen Corp., Carlsbad, CA) and Brucella selective supplement (Oxoid Ltd., Cambridge, United Kingdom) were inoculated with $100 \mu \mathrm{l}$ of homogenized tissue. The plates were incubated at $37^{\circ} \mathrm{C}$ in $5 \% \mathrm{CO}_{2}$ for 10 days. In addition, $1 \mathrm{ml}$ aliquot of homogenized lymph node was cultured at $37{ }^{\circ} \mathrm{C}$ for 10 days in Brucella selective broth with Brucella selective supplement (Oxoid Ltd., Cambridge, United Kingdom) before $100 \mu \mathrm{l}$ of inoculum was transferred to Brucella agar plates as described above and incubated under the same conditions. Growth of Brucella was checked daily. Routine biochemical and growth-based typing tests like parallel incubation with and without $\mathrm{CO}_{2}$ were performed on the isolates [14]. API $20 \mathrm{NE}$ test (BioMérieux, Marcy l'Etoile, France) was performed according to the manufacturer's instructions. Slide agglutination tests of the isolated strain was carried out using $\mathrm{A}, \mathrm{M}$ (monospecific sera against the $\mathrm{A}$ or $\mathrm{M}$ agglutinogen of Brucella spp. forming smooth /S/ colonies), and R (serum against Brucella spp. with rough /R/ colony form) sera (French Agency for Food, Environmental \& Occupational Health Safety /ANSES/, Maisons-Alfort Cedex, France).

DNA was extracted with the QIAamp DNA Mini Kit (Qiagen Inc., Valencia, CA) from 1 distinct colony and the upgraded Bruce-ladder and Suis-ladder PCR systems were used for the molecular identification of the isolated strain [15]. Next-generation sequencing technology was used to re-sequence the genome of the isolate. One hundred ng of DNA was subjected to enzymatic fragmentation using the reagents supplied in the NEBNext ${ }^{\circ}$ Fast DNA Fragmentation \& Library Prep Set for Ion Torrent $^{\mathrm{Tm}}$ kit (New England Biolabs, Hitchin, United Kingdom) according to the manufacturer's instructions. The adaptor ligation was performed using reagents from the same kit, whereas barcoded adaptors were retrieved from the Ion Xpress ${ }^{\text {TM }}$ Barcode Adapters (Life Technologies Inc., Waltham, MA, USA). The barcoded library DNA samples were column purified using the Gel/PCR DNA Fragments Extraction kit (Geneaid Biotech Ltd., Taipei, Taiwan). Then the eluted library DNA was run on $2 \%$ precast gel. Products between 300 and 350 bp were directly used without further purification in the PCR mixture of the NEBNext ${ }^{\circ}$ Fast DNA Fragmentation \& Library Prep Set for Ion Torrent ${ }^{\mathrm{tm}}$ kit (New England Biolabs). Library amplification involved 12 amplification and the products were purified by the Gel/PCR DNA Fragments Extraction kit (Geneaid). The DNA was eluted in $50 \mu \mathrm{l}$ nuclease free water and quantified fluorometrically on Qubit $^{\circ} 2.0$ equipment using the Qubit $^{\oplus}$ dsDNA BR Assay kit (Invitrogen). The appropriately diluted library DNA was used in emulsion PCR. This step was carried out according to the manufacturer's protocol using the Ion PGM Template kit on OneTouch v2 instrument. Enrichment of the templated beads (on Ion One Touch ES machine) and further steps of pre-sequencing set-up were performed according to the $200 \mathrm{bp}$ protocol of the manufacturer. The sequencing protocol recommended for Ion $\mathrm{PGM}^{\mathrm{m}}$ Sequencing Kit on a 316 chip was strictly followed.

Sequence data were curated and mapped onto the reference B. microti chromosome sequences (NC_013119, NC_013118) obtained from GenBank using the Lasergene Genomics Suite Software (DNASTAR Inc., Madison, WI, USA) and putative single nucleotide polymorphisms (SNPs) were identified between the two genomes under the following settings; mer size: $19 \mathrm{nt}$, minimum match percentage: 93 , minimum alignment length: 25 , maximum gap size: 30 , match score:10, mismatch penalty: 20 , gap penalty: 50 , gap extension penalty: 10 , alignment cutoff: 
200, SNP calculation method: haploid bayesian, P not reference percentage: $75 \%$, Phred score (Q call): 30, SNP percentage: 75-100 \%, coverage depth minimum: 5 . Validity of SNPs were confirmed by visual examination in the assembled sequences.

Multiple-locus variable-number tandem repeat analysis (MLVA) based on 16 variable-number tandem repeats (VNTR) (MLVA16) was performed on the isolated strain as described previously using singleplex PCR amplifications [16-18]. The reference strain B. suis Thomsen $\left(\right.$ ATCC $23445^{\mathrm{T}}$ ) was used as a standard during the amplifications to confirm appropriate fragment size estimations. The number of repeats was estimated from the amplicon sizes according to the 2013 Brucella allele assignment table (http://mlva.u-psud.fr). As the application of the MLVA-11 (including only loci from panels 1 and $2 \mathrm{~A}$ ) subset was found to be more useful in the comparison of strains with different origin than MLVA16 $[19,17]$, the evolutionary relatedness among the allelic profiles of the present isolate and B. microti strains available in the Brucella MLVA database was examined with the goeBURST algorithm for the compilation of minimum spanning tree in Phyloviz based on MLVA11 data [20]. The genotype of the reference strain of B. suis biovar. 5 (NCTC11996 ${ }^{\mathrm{T}}$ ) (http://mlva.u-psud.fr) was also included in the analysis as an outgroup.

\section{Results}

The submandibular lymph node sample of the wild boar did not show any gross pathological or histological changes and was negative with $B$. abortus, $B$. suis and
B. canis specific sera in the immunohistochemical examinations. The directly inoculated Brucella selective agar remained negative during the incubation period but colonies appeared in pure culture after two days incubation on the Brucella selective agar inoculated with the enriched Brucella selective broth. The colonies were small, translucent, had creamy consistency and displayed a brownish pigmentation after 3 days of incubation. The Gram-negative and modified acid-fast, small coccobacilli demonstrated oxidase, catalase, and urease activity, but failed to produce $\mathrm{H}_{2} \mathrm{~S}$. The isolate grew in the presence of $20 \mu \mathrm{g} / \mathrm{ml}$ thionin and basic fuchsin and did not require $\mathrm{CO}_{2}$ for its growth. The isolate showed strong agglutination with sera $\mathrm{A}$ and $\mathrm{M}$, but agglutination was not observed with serum R. The API 20 NE test identified it as Ochrobactrum anthropi with 99.9 \% identity, with positive reactions in nitrate reduction, urease activity, D-glucose, L-arabinose, D-mannose, $\mathrm{N}$-acetylglucosamine, D-maltose, adipic acid and malic acid assimilation tests and negative reactions for indole production, D-glucose fermentation, arginine dihidrolase tests, esculin and gelatin hydrolysis, $\beta$-galactosidase activity, and in D-mannitol, potassium gluconate, capric acid, trisodium citrate and phenylacetic acid assimilation reactions.

The isolate was identified as B. microti (strain ID: HUNBmi-01) with the upgraded "Bruce- and Suis-ladder" methods. In Bruce-ladder v2.0 1682, 1071, 774, 587, 450, 272, 152, and the B. microti specific 510 bp fragments were amplified, while in Suis-ladder 774 and 197 bp amplicons appeared (Fig. 1). The whole genome sequence



Fig. 1 Results of upgraded "Bruce- and Suis-ladder" PCRs of HUN-Bmi-01 strain. left side Bruce-ladder v2.0 PCR with 1682, 1071, 774, 587, 510, 450, 272, and 152 bp amplicons. M: 100 bp DNA marker, S: B. suis, C: B. canis, O: B. ovis, A: B. abortus. right side Suis-ladder PCR with 774 and 197 bp amplicons. M: 100 bp DNA marker, S1: B. suis biovar. 1, S2: B. suis biovar. 2 
Table 1 SNPs identified in the new $B$. microti isolate

\begin{tabular}{|c|c|c|c|c|c|c|c|c|c|c|}
\hline Chromosome & $\begin{array}{l}\text { Reference } \\
\text { sequence ID }\end{array}$ & $\begin{array}{l}\text { Position in reference } \\
\text { sequence }\end{array}$ & $\begin{array}{l}\text { Reference } \\
\text { base }\end{array}$ & $\begin{array}{l}\text { Base in the studied B. microti } \\
\text { strain (HUN-Bmi-01) }\end{array}$ & $\begin{array}{l}\text { Location of } \\
\text { mutation }\end{array}$ & $\begin{array}{l}\text { Impact of } \\
\text { mutation }\end{array}$ & SNP \% & $\begin{array}{l}P \text { not reference } \\
\text { value }\end{array}$ & $\begin{array}{l}\text { Phred } \\
\text { score }\end{array}$ & $\begin{array}{l}\text { Coverage } \\
\text { depth }\end{array}$ \\
\hline I & NC_013119 & 63814 & A & $G$ & BMI_159 & synonymous & $99.1 \%$ & $100.0 \%$ & 60.000 & 119 \\
\hline | & NC_013119 & 115266 & C & A & cysA & non-synonymous & $96.4 \%$ & $100.0 \%$ & 60.000 & 84 \\
\hline 1 & NC_013119 & 220835 & G & $\mathrm{T}$ & BMI_I210 & non-synonymous & $100.0 \%$ & $100.0 \%$ & 60.000 & 140 \\
\hline । & NC_013119 & 300834 & G & A & $\mathrm{fadD}$ & synonymous & $99.3 \%$ & $100.0 \%$ & 60.000 & 160 \\
\hline । & NC_013119 & 362076 & T & C & $x d h B$ & synonymous & $99.2 \%$ & $100.0 \%$ & 60.000 & 126 \\
\hline | & NC_013119 & 530242 & N & A & BMI_I534 & synonymous & $86.1 \%$ & $100.0 \%$ & 60.000 & 94 \\
\hline । & NC_013119 & 530273 & N & A & BMI_I534 & non-synonymous & $75.4 \%$ & $100.0 \%$ & 39.876 & 106 \\
\hline | & NC_013119 & 549069 & G & A & intergenic region & & $100.0 \%$ & $100.0 \%$ & 60.000 & 109 \\
\hline | & NC_013119 & 643213 & T & C & intergenic region & & $99.2 \%$ & $100.0 \%$ & 60.000 & 134 \\
\hline । & NC_013119 & 806268 & A & G & intergenic region & & $98.0 \%$ & $100.0 \%$ & 60.000 & 153 \\
\hline । & NC_013119 & 1078051 & T & C & gyrA & non-synonymous & $100.0 \%$ & $100.0 \%$ & 60.000 & 146 \\
\hline 1 & NC_013119 & 1141643 & C & T & BMI_|1167 & synonymous & $100.0 \%$ & $100.0 \%$ & 60.000 & 123 \\
\hline । & NC_013119 & 1145284 & C & T & pyrH & non-synonymous & $82.1 \%$ & $100.0 \%$ & 60.000 & 95 \\
\hline । & NC_013119 & 1251949 & G & T & BMI_I1296 & synonymous & $100.0 \%$ & $100.0 \%$ & 60.000 & 23 \\
\hline | & NC_013119 & 1252016 & A & T & BMI_11296 & non-synonymous & $100.0 \%$ & $100.0 \%$ & 60.000 & 13 \\
\hline 1 & NC_013119 & 1778954 & G & A & BMI_|1855 & synonymous & $95.2 \%$ & $100.0 \%$ & 60.000 & 146 \\
\hline 1 & NC_013119 & 1790391 & T & G & BMI_|1868 & synonymous & $93.1 \%$ & $100.0 \%$ & 60.000 & 132 \\
\hline । & NC_013119 & 1790394 & C & A & BMI_|1868 & synonymous & $94.0 \%$ & $100.0 \%$ & 60.000 & 152 \\
\hline । & NC_013119 & 1853511 & C & T & BMI_|1931 & non-synonymous & $98.8 \%$ & $100.0 \%$ & 60.000 & 171 \\
\hline$\|$ & NC_013118 & 109915 & A & G & BMI_II112 & synonymous & $99.4 \%$ & $100.0 \%$ & 60.000 & 178 \\
\hline$\|$ & NC_013118 & 483021 & G & A & BMI_II495 & synonymous & $100.0 \%$ & $100.0 \%$ & 60.000 & 174 \\
\hline$\|$ & NC_013118 & 689243 & A & G & intergenic region & & $100.0 \%$ & $100.0 \%$ & 60.000 & 11 \\
\hline$\|$ & NC_013118 & 739665 & C & A & intergenic region & & $100.0 \%$ & $100.0 \%$ & 60.000 & 148 \\
\hline$\|$ & NC_013118 & 816002 & C & T & BMI_II819 & synonymous & $92.2 \%$ & $100.0 \%$ & 60.000 & 90 \\
\hline$\|$ & NC_013118 & 834372 & $\mathrm{~T}$ & C & BMI_II841 & synonymous & $97.8 \%$ & $100.0 \%$ & 60.000 & 232 \\
\hline$\|$ & NC_013118 & 834392 & N & G & BMI_II841 & synonymous & $98.0 \%$ & $100.0 \%$ & 60.000 & 204 \\
\hline$\|$ & NC_013118 & 951779 & G & C & intergenic region & & $80.1 \%$ & $100.0 \%$ & 60.000 & 563 \\
\hline$\|$ & NC_013118 & 978988 & C & A & BMI_II983 & synonymous & $98.3 \%$ & $100.0 \%$ & 60.000 & 124 \\
\hline$\|$ & NC_013118 & 1186061 & C & $\mathrm{T}$ & BMI_II1178 & non-synonymous & $100.0 \%$ & $100.0 \%$ & 60.000 & 138 \\
\hline$\|$ & NC_013118 & 1186062 & C & T & BMI_II1178 & non-synonymous & $100.0 \%$ & $100.0 \%$ & 60.000 & 138 \\
\hline
\end{tabular}


of the isolate was deposited in GenBank [Accession number SRP053188]. The number of reads used for mapping was 2,705,699 (1,725,428 on chromosome 1 and 980,271 on chromosome 2), while 122,318 reads were discarded during alignment. The median coverage was $142 \mathrm{X}$ on chromosome 1 and 140X on chromosome 2 . In the whole genome sequence, 19 SNPs were identified on chromosome 1 and 11 SNPs on chromosome 2 compared to the B. microti reference genome available in GenBank (Table 1). For the 30 SNPs, 6 were in intergenic regions (non-coding) and 24 were within known gene regions; 15 of intragenic SNPs were synonymous mutations and 9 were non-synonymous. The MLVA16 analysis yielded a novel profile (BH_5: 4-5-12-13-5-2-5-6-7-7-9-10-13-12-46, in order of loci Bruce06-08-11-12-42-43-45-55-18-1921-04-07-09-16-30) compared to the other 11 B. microti strains available in the MLVA bank. The genetic relatedness of the strains based on the MLVA11 subset is displayed on Fig. 2.

\section{Discussion}

The hunting area in Hungary where the wild boar was harvested is close to Austria where several previous $B$. microti isolates originated. Hungary is located in Central Europe and current data indicate that countries in this area are enzootic foci of $B$. microti. We hypothesize that the wild boar acquired the $B$. microti strain while eating a rodent, a carcass (e.g., dead fox), or simply rooting in the soil. The hunters did not report any gross pathological lesions in other parts of the carcass, so it seems likely that the wild boar did not develop any obvious clinical disease. Thus we suspect that wild boar merely serves as a reservoir species capable of maintaining and spreading the pathogen in nature.
The negative results of both the S and R type Brucellaspecific immunohistochemical reactions imply that the amount of $B$. microti in the lymph node was below the detection limit of this method, which is also supported by the finding that the strain could only be isolated after enrichment in Brucella selective broth. These results and the lack of histological lesions in lymph node further support the hypothesis that the wild boar was only an asymptomatic carrier of this bacterium.

The morphological, growth and biochemical characteristics of the isolated $B$. microti strain were congruent with the description of Scholz et al. [7], including the described brownish pigmentation of the colonies after 3 days incubation. The isolate displayed a unique agglutination reaction, agglutinating with anti- $\mathrm{A}$ and anti-M but not with anti- $\mathrm{R}$ monospecific sera. The first common vole strains only agglutinated with anti-M serum [7], but Al Dahouk et al. [12] reported several different agglutination patterns; despite the $\mathrm{M}$ antigen dominancy a fox isolate only agglutinated with anti-A serum, while the soil isolates agglutinated all three monospecific sera.

The observed 30 SNPs between the whole genome sequence of the Czech common vole and Hungarian wild boar strain is surprisingly few, suggesting relatively high genetic homogeneity within B. microti in Central Europe. We omitted potential sources of variation such as multi-copy genetic elements, insertion sequences, and repeat regions from the SNP analysis. Thus, our estimate of the number of SNPs is a conservative one but is more likely to represent biologically meaningful differences. Moreover, SNPs from homologous loci have been demonstrated as reliable for phylogenetic analysis of Brucella species because of their coverage of the entire genome, relative stability over evolutionary time, ease of comparison, and inclusion of intergenic regions [21]. Therefore the primary aim of SNP analysis was to phylogenetically

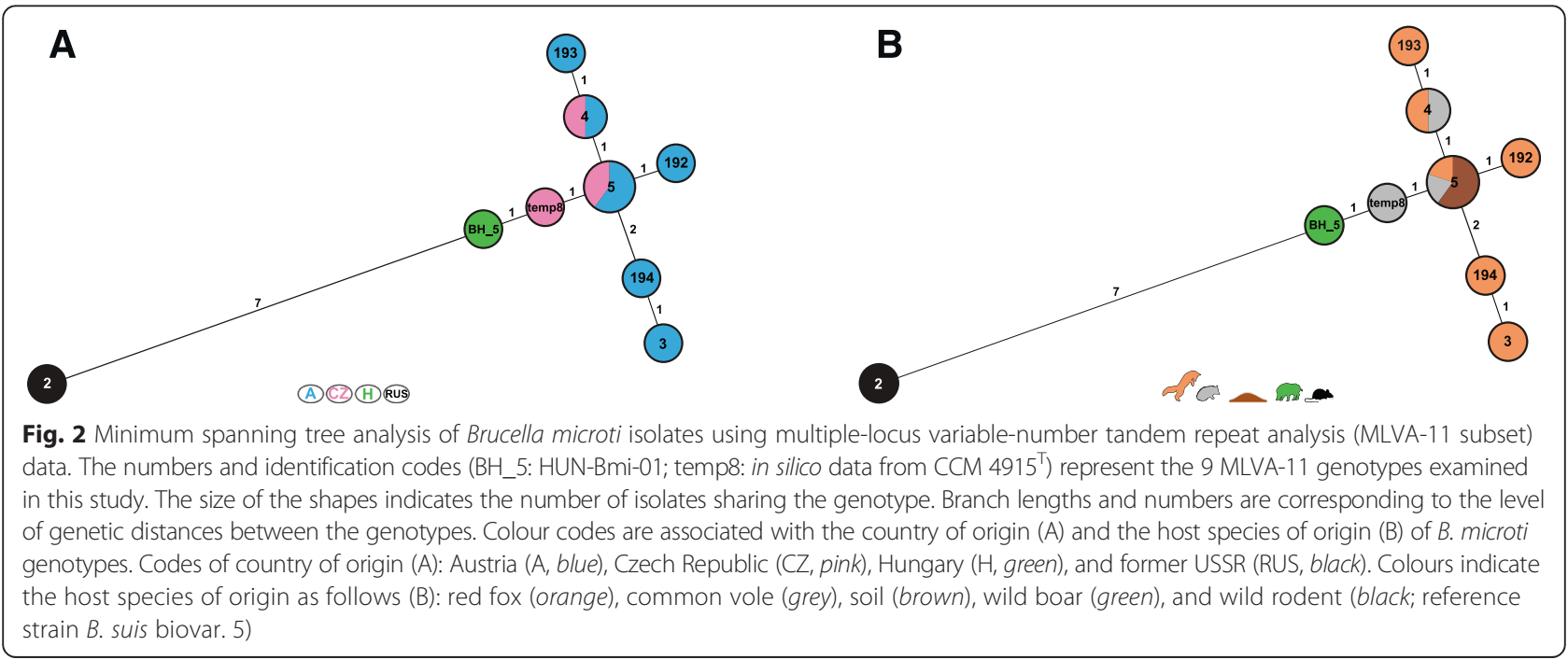


(at large evolutionary scale level) compare the present Hungarian B. microti isolate with the Czech B. microti strain.

The highly mutable genetic markers, VNTRs, are not captured in the re-sequenced draft genome. However, our amplicon sequencing of these loci allowed for placement of our isolate within a MLVA framework, indicating that the Hungarian wild boar B. microti isolate is clearly differentiated from the common vole, fox and soil isolates originated from Austria and the Czech Republic. The question regarding the source of infection in wild boar (i.e., common vole, fox, soil or other host) remains open and additional efforts to better understand the epidemiology and ecology of B. microti are needed.

\section{Conclusion}

This is the first isolation of Brucella microti from a wild boar, and also the first isolation of this species in Hungary. The information gained through bacteriological, histological, immunohistological and molecular analysis with emphasis on whole genome re-sequencing highly contribute to our knowledge of the host range, geographic distribution and genomic organization of B. microti.

\section{Abbreviations \\ MLVA: Multiple-locus variable number tandem repeat analysis; SNP: Single nucleotide polymorphism; VNTR: Variable number tandem repeats.}

\section{Competing interests}

The authors declare that they have no competing interests.

\begin{abstract}
Authors' contributions
ZR isolated the strain, performed the morphological, biochemical tests, multiplex PCRs and wrote the manuscript. ZK performed MLVA. ÁD, KD, JTF analyzed the whole-genome sequence data. KB and SM performed the wholegenome re-sequencing. LS performed the pathological, histological and immunohistochemical examinations. SJ performed morphological tests. MG designed the study, analysed the data and wrote the manuscript. All authors read and approved the final manuscript.
\end{abstract}

\section{Acknowledgements}

This study was supported by the Lendület (Momentum) programme of the Hungarian Academy of Sciences. The authors acknowledge Ildikó Szombatiné Boda for laboratory assistance.

\begin{abstract}
Author details
${ }^{1}$ Veterinary Diagnostic Directorate, National Food Chain Safety Office, P.O. Box 21581 Budapest, Hungary. ${ }^{2}$ Institute for Veterinary Medical Research, Centre for Agricultural Research, Hungarian Academy of Sciences, Hungária körút 21, 1143 Budapest, Hungary. ${ }^{3}$ University of New Hampshire, Durham, New Hampshire, USA.
\end{abstract}

Received: 26 February 2015 Accepted: 18 June 2015

Published online: 11 July 2015

\section{References}

1. Foster G, Osterman BS, Godfroid J, Jacques I, Cloeckaert A. Brucella ceti sp. nov. and Brucella pinnipedialis sp. nov. for Brucella strains with cetaceans and seals as their preferred hosts. Int J Syst Evol Microbiol. 2007;57:2688-93.

2. Scholz HC, Nöckler K, Göllner C, Bahn P, Vergnaud G, Tomaso H, Al Dahouk S, Kämpfer P, Cloeckaert A, Maquart M, Zygmunt MS, Whatmore AM, Pfeffer
M, Huber B, Busse H-J, De BK. Brucella inopinata sp. nov., isolated from a breast implant infection. Int J Syst Evol Microbiol. 2010;60:801-8.

3. Eisenberg T, Hamann HP, Kaim U, Schlez K, Seeger H, Schauerte N, Melzer F, Tomaso H, Scholz HC, Koylass MS, Whatmore AM, Zschöck M. Isolation of potentially novel Brucella spp. from frogs. Appl Environ Microbiol. 2012;78:3753-5.

4. Whatmore AM, Dale E-J, Stubberfield E, Muchowski J, Koylass M, Dawson C, Gopaul KK, Perrett LL, Jones M, Lawrie A. Isolation of Brucella from a White's tree frog (Litoria caerulea). JMM Case Reports. 2015; doi: 10.1099/jmmcr.0.000017.

5. Whatmore AM, Davison N, Cloeckaert A, Al Dahouk S, Zygmunt MS, Brew SD, Perrett LL, Koylass MS, Vergnaud G, Quance C, Scholz HC, Dick EJ Jr, Hubbard G, Schlabritz-Loutsevitch NE. Brucella papionis sp. nov., isolated from baboons (Papio spp.). J Syst Evol Microbiol. 2014;64:4120-8.

6. Hubálek Z, Scholz HC, Sedláček I, Melzer F, Sanogo YO, Nesvadbová J. Brucellosis of the Common Vole (Microtus arvalis). Vector Borne Zoonotic Dis. 2007;7:679-88.

7. Scholz HC, Hubalek Z, Sedlácek I, Vergnaud G, Tomaso H, Al Dahouk S, Melzer F, Kämpfer P, Neubauer H, Cloeckaert A, Maquart M, Zygmunt MS, Whatmore AM, Falsen E, Bahn P, Göllner C, Pfeffer M, Huber B, Busse HJ, Nöckler K. Brucella microti sp. nov., isolated from the common vole Microtus arvalis. Int J Syst Evol Microbiol. 2008;58:375-82. doi:10.1099/ijs.0.65356-0.

8. Scholz HC, Hubalek Z, Nesvadbova J, Tomaso H, Vergnaud G, Le Flèche P, Whatmore AM, Al Dahouk S, Krüger M, Lodri Cs, Pfeffer M. Isolation of Brucella microti from Soil. Emerg Infect Dis. 2008;14:1316-7.

9. Scholz HC, Hofer E, Vergnaud G, Le Fleche P, Whatmore AM, Al Dahouk S, Pfeffer M, Krüger M, Cloeckaert A, Tomaso H. Isolation of Brucella microti from mandibular lymph nodes of red foxes, Vulpes vulpes, in lower Austria. Vector Borne Zoonotic Dis. 2009;9:153-6.

10. Audic S, Lescot M, Claverie JM, Scholz HC. Brucella microti: the genome sequence of an emerging pathogen. BMC Genomics. 2009;10:352.

11. Jiménez de Bagüés MP, Ouahrani-Bettache S, Quintana JF, Mitjana O, Hanna N, Bessoles S, Sanchez F, Scholz HC, Lafont V, Köhler S, Occhialini A. The new species Brucella microti replicates in macrophages and causes death in murine models of infection. J Infect Dis. 2010;202:3-10. doi:10.1086/653084.

12. Al Dahouk S, Hofer E, Tomaso H, Vergnaud G, Le Flèche P, Cloeckaert A, Koylass MS, Whatmore AM, Nöckler K, Scholz HC. Intraspecies biodiversity of the genetically homologous species Brucella microti. Appl Environ Microbiol. 2012;78:1534-43.

13. Gyuranecz M, Szeredi L, Rónai Z, Dénes B, Dencso L, Dán Á, Pálmai N, Hauser Z, Lami E, Makrai L, Erdélyi K, Jánosi S. Detection of Brucella canis-induced reproductive diseases in a kennel. J Vet Diagn Invest. 2011;23:143-7.

14. Alton $\mathrm{GG}$, Jones $\mathrm{LM}$, Angus RD, Verger JM. Bacteriological methods. In: Techniques for the Brucellosis laboratory. Paris, France: Institut National de la Recherche Agronomique; 1988. p. 13-61.

15. López-Goñi I, García-Yoldi D, Marín CM, de Miguel MJ, Barquero-Calvo E, Guzmán-Verri C, Albert D, Garin-Bastuji B. New Bruce-ladder multiplex PCR assay for the biovar typing of Brucella suis and the discrimination of Brucella suis and Brucella canis. Vet Microbiol. 2011;154:152-5. doi:10.1016/j.vetmic.

16. Al Dahouk S, Le Flèche P, Nöckler K, Jacques I, Grayon M, Scholz HC, Tomaso H, Vergnaud G, Neubauer H. Evaluation of Brucella MLVA typing for human brucellosis. J Microbiol Methods. 2007;69:137-45.

17. Kreizinger Z, Foster JT, Rónai Z, Sulyok KM, Wehmann E, Jánosi S, Gyuranecz M. Genetic relatedness of Brucella suis biovar 2 isolates from hares, wild boars and domestic pigs. Vet Microbiol. 2014;172(3-4):492-8.

18. Le Flèche P, Jacques I, Grayon M, Al Dahouk S, Bouchon P, Denoeud F, Nöckler K, Neubauer H, Guilloteau LA, Vergnaud G. Evaluation and selection of tandem repeat loci for a Brucella MLVA typing assay. BMC Microbiol. 2006;6:9.

19. Kilıç S, Ivanov IN, Durmaz R, Bayraktar MR, Ayaşlıoğlu E, Uyanık MH, Alışkan H, Yaşar E, Bayramoğlu G, Arslantürk A, Vergnaud G, Kantardjiev TV. Multiple-locus variable-number tandem-repeat analysis genotyping of human Brucella isolates from Turkey. J Clin Microbiol. 2011;49:3276-83.

20. Francisco AP, Vaz C, Monteiro PT, Melo-Cristino J, Ramirez M, Carriço JA. PHYLOViZ: phylogenetic inference and data visualization for sequence based typing methods. BMC Bioinformatics. 2012;13:87.

21. Foster JT, Beckstrom-Sternberg SM, Pearson T, Beckstrom-Sternberg JS, Chain PS, Roberto FF, Hnath J, Brettin T, Keim P. Whole-genome-based phylogeny and divergence of the genus Brucella. J Bacteriol. 2009;8:2864-70. 